\title{
Individual and community-level determinants of childhood vaccination in Ethiopia
}

\author{
Setegn Muche Fenta ${ }^{1 *}$ (D) and Haile Mekonnen Fenta ${ }^{2}$
}

\begin{abstract}
Background: Vaccines are one of our most important tools for preventing outbreaks and keeping the world safe. Most unvaccinated children live in the poorest countries including Ethiopia. Therefore, this study aimed to identify the determinants of vaccination coverage among children aged12-23 months in Ethiopia.

Methods: A cross-sectional secondary data were obtained from the 2016 Ethiopian Demographic and Health Survey data (EDHS). A total of 1929 children were included. A Multilevel Proportional Odds Model was used to identify the individual and community-level factors associated with child vaccination.

Result: Among 1, 929 children, only $48.6 \%$ (95\% Cl: 46.3 to 50.8\%) were fully vaccinated while $37.8 \%$ (95\% Cl: 35.7 to $40.1 \%$ ) were partially vaccinated.. The multilevel ordinal logistic regression model reveled that housewife mother $(\mathrm{AOR}=1.522,95 \% \mathrm{Cl}: 1.139,2.034)$, institutional delivery ( $\mathrm{AOR}=2.345,95 \% \mathrm{Cl}: 1.766,3.114$ ), four or above antenatal care visits $(A O R=2.657 ; 95 \% \mathrm{Cl}: 1.906,3.704)$, children of mothers with secondary or higher education ( $A O R=2.008$; 95\% Cl: 1.209, 3.334), Children whose fathers primary education ( $A O R=1.596 ; 95 \% \mathrm{Cl}: 1.215,2.096)$, from the rich households ( $A O R=1.679 ; 95 \% \mathrm{Cl}: 1.233,2.287$ ) were significantly associated with childhood vaccination.

Conclusion: Child vaccination coverage in Ethiopia remains low. Therefore, there is a need to increase child vaccination coverage by promoting institutional delivery and prenatal care visits, as well as maternal tetanus immunization. Besides, public initiatives needed to improve child vaccination coverage, women's and husband's education, poor women, and further advancement of health care services for poor women, housewife women, women living in remote areas should be made to maintain further improvements in child vaccination. Furthermore, policies and programs aimed at addressing cluster variations in child vaccination need to be formulated and their implementation must be strongly pursued.
\end{abstract}

Keywords: Child vaccination, Ordinal, Multilevel, Ethiopia

\section{Background}

In 2019, nearly 5.2 million children died, and about 14 , 000 children still die globally every day. About $80 \%$ of the 5.2 million child deaths have occurred in subSaharan Africa and Central and Southern Asia. SubSaharan Africa remains the country with the highest

\footnotetext{
*Correspondence: setegn14@gmail.com

'Department of Statistics, Faculty of Natural and Computational Sciences, Debre Tabor University, Debre Tabor, Ethiopia

Full list of author information is available at the end of the article
}

child mortality rate in the world [1-3]. Ethiopia has one of the highest rates of child deaths and disabilities in the world. More than 704 children die every day from easily preventable diseases $[4,5]$.

Vaccination is one of the safest and cost-effective interventions to reduce childhood morbidity and mortality [6]. Vaccines prevent an estimated 2.5 million deaths among children under five every year. In 2019, 19.4 million infants did not receive basic vaccines $[4,7,8]$. Ethiopia is the fifth country in the world with a large

C C The Author(s). 2021 Open Access This article is licensed under a Creative Commons Attribution 4.0 International License, which permits use, sharing, adaptation, distribution and reproduction in any medium or format, as long as you give appropriate credit to the original author(s) and the source, provide a link to the Creative Commons licence, and indicate if changes were made. The images or other third party material in this article are included in the article's Creative Commons licence, unless indicated otherwise in a credit line to the material. If material is not included in the article's Creative Commons licence and your intended use is not permitted by statutory regulation or exceeds the permitted use, you will need to obtain permission directly from the copyright holder. To view a copy of this licence, visit http://creativecommons.org/licenses/by/4.0/ The Creative Commons Public Domain Dedication waiver (http://creativecommons.org/publicdomain/zero/1.0/) applies to the data made available in this article, unless otherwise stated in a credit line to the data. 
number of unvaccinated children. In 2018, more nine thousand children were not vaccinated for the third dose of the pentavalent vaccine, and more than 1.2 million children were not vaccinated with the first dose of measles vaccines [5]. Sustainable improvements in service delivery are needed to protect Ethiopian children from unnecessary suffering and death $[9,10]$.

Various studies have been conducted to identify the determinants of childhood vaccination in different developing countries including Ethiopia [11-17]. These studies investigated the determinants of vaccination coverage through binary logistic regression analysis. The response variable for the above studies was considered as binary (fully vaccinated and not fully vaccinated); as a result, the binary logistic regression model was employed in all the cases. In the case of binary logistic regression, infants who received one or more vaccines considered not vaccinated to fulfill the requirements of binary logistic regression provides sufficient information for studying the pattern of infants who received one or more vaccines. However, the vaccination status of a child is usually classified as fully vaccinated, partially (incomplete) vaccinated, and not vaccinated by considering natural ordering. To answer this, we apply the ordinal logistic regression model to identify the determinants factors of childhood vaccination.

Furthermore, the application of an ordinary logistic regression analysis approach to analyze data in a hierarchical design (i.e. children nested within communities) undermines the assumptions of independence of regression. This paper used a multi-level logistic regression analysis to resolve these limitations and to further assess the significant impact of individual and community-level variables on Ethiopia [18-20]. Therefore, this study aimed to identify the determinants of vaccination coverage among children aged 12-23 months in Ethiopia using multilevel ordinal logistic regression.

\section{Methods}

Data source and study design

The data for this study was taken from the 2016 EDHS. It is the fourth and most recent nationally representative dataset of demographic and health surveys. The sample was taken using a two-stage stratified sampling. The first stage of the selection was 645 PSU with 202 EAs urban and 443 EAs rural areas based on the 2007 Ethiopian Population and Housing Census (PHC) of the Ethiopian Central Statistics Agency (CSA). All women aged 15-49 years who were usually members of the selected households were eligible for the female survey. All men aged 15-59 years who were usually members of the selected households were eligible for the male survey. Children age 12-23 months with missing age of child and outcome variable were excluded from the study. The relevant data (children recode) on vaccination of children 12-23 months of age were extracted from the EDHS 2016.

\section{Variable of the study Outcome variable}

Child vaccination status was the outcome variable and categorized into three: fully vaccinated, partially (incomplete) vaccinated, and not vaccinated. According to the WHO guideline vaccine $[5,21,22]$, full vaccinated is defined as a child between 12 to 23 months who received one dose of Bacille Calmette-Guerin (BCG), at least three doses of pentavalent, three doses of oral polio vaccine (OPV), and one dose of measles vaccine. Partially (incomplete) vaccinated is defined as a child 12 to 23 months who had missed at least one of the eight vaccines [20, 23, 24]. Not vaccinated is also defined as a child 12 to 23 months who didn't receive any vaccine $[20,24]$.

\section{Independent variables}

The independent variables were selected based on prior knowledge and published literature [11, 12, 14, 25-28]. These variables include sex of child, birth order, place of delivery, maternal education, maternal age, number of ANC visits, postnatal care, sex of a child, presence of vaccination card, parental education, parental occupation, household size, wealth index, exposure to mass media, number of living children, mothers tetanus injections received, size of child at birth, ever had terminated pregnancy, wanted last-child, sex of household head, marital status, place of residence, and geographic region.

\section{Statistical analysis}

$R$ version 3.4.4 statistical software was used to analyze the data. Frequencies and percentages were used to describe the categorical variables. The models for ordinal outcome variables are important in many areas of research since respondents are often classified on an ordinal or graded scale. More importantly, it is often the cases of the respondents are observed nested within clusters or communities (i.e children nested with community/clusters) and so the use of the ordinal regression model which assumes the observations are independent which is problematic. In this case, the multilevel regression model better analyzes the response measurements [29, 30]. A Multilevel Proportional Odds Model (MPOM) was used to identify the individual and community-level factors associated with child vaccination. The proportionality assumptions for MPOM were checked by using Chi-square parallel line tests [29]. MPOM model contains both fixed and random effects. The fixed effect represents the mean response, while the random effect represents the individual level responses. The fixed effect was reported in terms of adjusted proportional odds ratio (APOR) with their 95\% CI. All 
variables with $p$-values $\leq 0.05$ have been considered statistically significant. The random effect was also measured by Proportional Change in Variance (PCV) and Intra-class Correlation Coefficient (ICC). Four consecutive models (model I-IV) were observed. The model I (null model) was run to test the inter-group (community) variability on child vaccination and to decide whether the data is fit for multilevel modeling or not. Model II includes only individuallevel factors. Model III includes only community-level factors. Model IV includes both individual and community-level factors [19, 20].

\section{Model fit statistics}

Deviance Information Criteria (DIC) and Akaike's Information Criterion (AIC) were used to compare and select the model. The model with the minimum value of the information criterion was best fits the data $[19,20]$.

\section{Result}

\section{Vaccination coverage in Ethiopia}

The full vaccination coverage in Ethiopia was 48.6\%. The majority, $71 \%$ of the children received BCG. Three fourth percent of the children received both Pentavalent1 and Polio 2. Eighty-two percent the children of received Polio 1. More than half, 59 of them received Measles vaccination. Besides, Vaccine specific coverage for Pentavalent 2, Pentavalent 3, and Polio 2 were 66, 57 , and $74 \%$, respectively (Figs. 1 and 2 ).

\section{Socio-demographic and economic characteristics of parents and children}

A total of 1929 women with children 12-23 months of old were included in the study. Regarding parental educational status, $50.5 \%$ of fathers and $60.7 \%$ of mothers had no formal education; while $30.4 \%$ of fathers and $26.3 \%$ of mothers attended primary school. More than half percent of mothers (50.7\%) were in the age group of 25-34 years. Nearly $60 \%$ of households had a poor wealth index and78.8\% of the respondents were living in rural areas. More than three fourth percent of households were headed by males. Almost all (93.4\%) mothers are married, and about half (51\%) of the children were female. About 47.7\%, of mothers, had Muslim beliefs and $35.5 \%$ had not ever got antenatal visits (Table 1 ).

\section{Determinants of vaccination coverage among children aged 12-23 months Multilevel analysis (fixed-effect analysis)}

The results of the multilevel proportional odds model were summarized in Table 2. The score test of proportional odds assumption is found insignificant at 5\% level of significance revealed that odds assumption is satisfied. The final selected model (model IV) showed that place of delivery, maternal education, number of ANC visits, presence of vaccination card, maternal occupation, mother and father education, wealth index, mothers tetanus injections received, wanted last-child, place of residence, community-level maternal education, community-level wealth index, community-level media exposure, and geographic region were factors significantly associated with childhood vaccination. Housewife women were 1.522 (AOR $=1.522,95 \% \mathrm{CI}: 1.139,2.034)$ times more likely to be partially or fully vaccinated than those employed women. Children who were born at health facilitieswere 2.345 ( $\mathrm{AOR}=2.345,95 \% \mathrm{CI}: 1.766,3.114)$ times more likely to be partially or fully vaccinated than those children who were born at home. Children whose mothers made ANC visits at least 4 times during the pregnancy were2.657 (AOR =

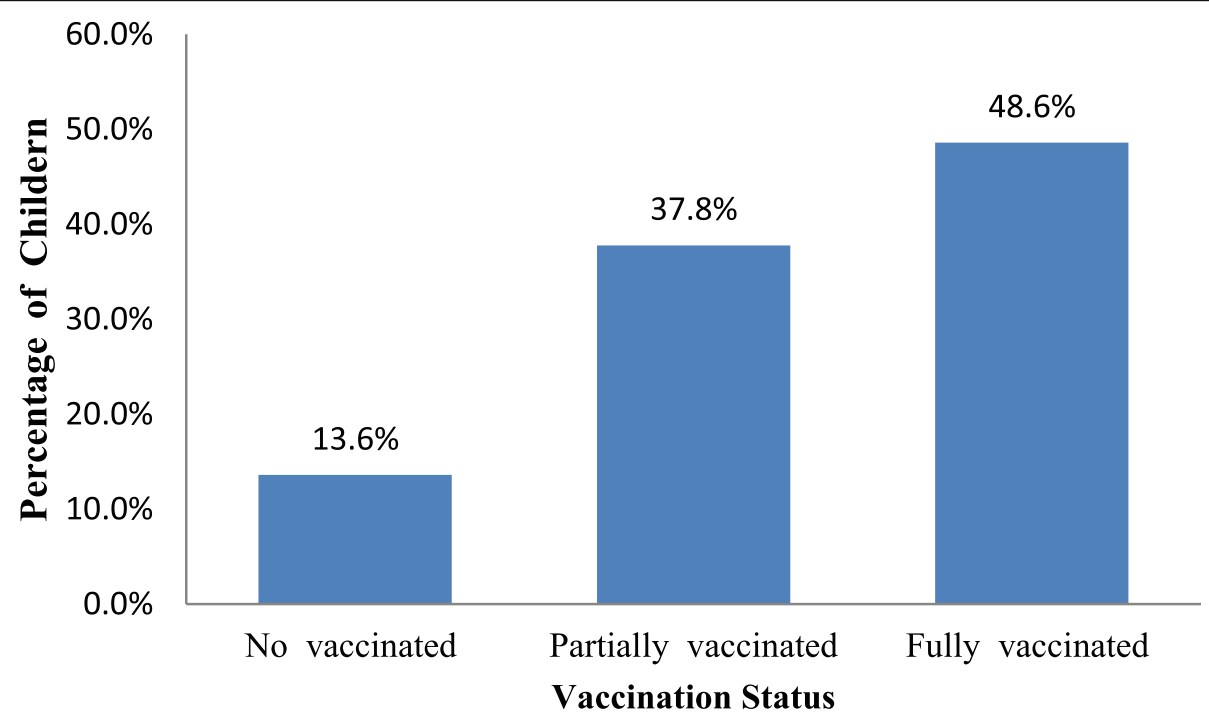

Fig. 1 Child vaccination coverage in Ethiopia 


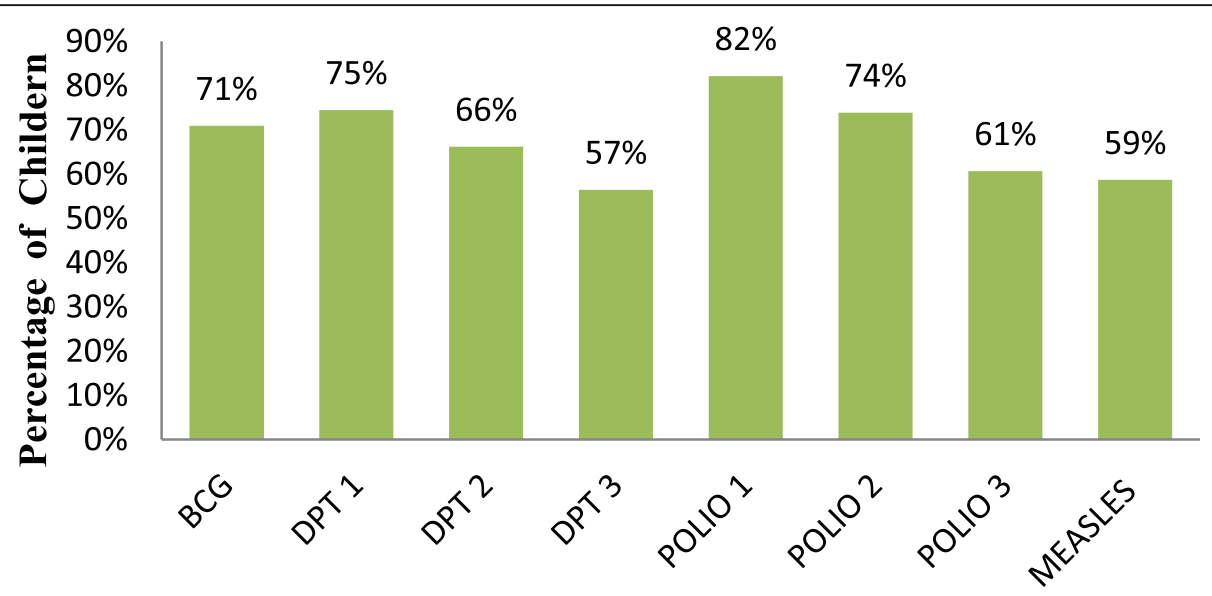

Fig. 2 Vaccine specific coverage among children aged 12-23 months in Ethiopia, 2016 EDHS

2.657; 95\% CI: $1.906,3.704)$ times more likely to be partially or fully vaccinated than children whose mothers who have not have any antenatal follow up. Compared with non-educated mothers, the odds of partially or fully vaccinated children with mothers who have attended secondary and above education were2.008 times $(\mathrm{AOR}=$ 2.008; 95\% CI:1.209, 3.334). Likewise, compared to noneducated fathers, the odds of partially or fully vaccinated children for father's attended primary education were increased by $59.6 \%$ (AOR $=1.596 ; 95 \%$ CI: $1.215,2.096$ ). Children in households in the middle wealth quintile as compared to the poorest had 1.446 (AOR $=1.446 ; 95 \% \mathrm{CI}$ : $1.045,2.002)$ times more likely to be partially or fully vaccinated. Similarly, children in households in the richer wealth quintile compared to the poorest had 1.679 $(\mathrm{AOR}=1.679 ; 95 \% \mathrm{CI}: 1.233,2.287)$ times more likely to be partially or fully vaccinated. The likelihood of being partially or fully vaccinated children among Muslim respondents was 0.445 ( $\mathrm{AOR}=0.445,95 \% \mathrm{CI}: 0.305,0.649$ ) times less likely than that for Orthodox Christian respondents. Besides, the probability of being partially or fully vaccinated children among protestant and other respondents was $0.444(\mathrm{AOR}=0.444,95 \% \mathrm{CI}$ : 0.290, 0.678) times less likely than that for Orthodox Christian respondents (Table 2).

A child living in a rural area was 0.505 (AOR=; 95\% CI: $0.284,0.898)$ times less likely to be partially or fully vaccinated than a child who was urban residents. Children live in Afar (AOR $=0.117 ; 95 \% \mathrm{CI}$ : 0.055, 0.250), Amhara $(\mathrm{AOR}=0.517 ; 95 \% \mathrm{CI}: 0.279,0.959)$, Oromia $(\mathrm{AOR}=2.533 ; 95 \% \mathrm{CI}: 1.320,4.861)$, Somali $(\mathrm{AOR}=$ 0.234; 95\% CI: 0.121, 0.453), Gambela ( $\mathrm{AOR}=0.170$; 95\% CI: $0.080,0.360$ ) were less likely to be partially or fully vaccinated as compared to children live in Tigray. Children living in communities with a high level of maternal education had increased by $81.4 \%(\mathrm{AOR}=1.814$; $95 \%$ CI: $1.206,2.729)$ of partially or fully vaccinated as compared to those children living in communities with low maternal education level. Children residing in communities with a high proportion of wealth index had 2.158 (AOR $=2.158 ; 95 \%$ CI: 1.333, 3.491) times higher odds of partial or full vaccinated as compared to children residing in communities with a low proportion of wealth index. Furthermore, children living in communities with a high proportion of media exposure were $1.758(\mathrm{AOR}=1.758 ; 95 \% \mathrm{CI}: 1.135,2.725)$ times more likely to be partially or fully vaccinated as compared to those children living in communities with a low proportion of media exposure (Table 2).

\section{Multilevel analysis (random-effects analysis)}

The result of random effect analysis has been presented in Table 3. The variation of child vaccination was different across communities. The null model indicated that $55.88 \%$ of the total variability for child vaccination was due to differences between clusters, with the remaining unexplained $44.12 \%$ which is accounted for by individual differences. The highest $(89.73 \%)$ PCV in the full model (model IV), revealed that $89.73 \%$ of the community-level variation on child vaccination has been explained by the combined factors at both the individual and community levels. The MOR value of child vaccination was 6.95 in the null model; this indicated that there was variation between communities (clustering) since 6.95times higher than the reference $(\mathrm{MOR}=1)$. The unexplained community variation child vaccination was reduced to a MOR of 1.86 when all factors were included in the model. This showed that when all factors are measured, the effects of clustering are still statistically significant in the full models (Table 3).

\section{Discussion}

This study was conducted to investigate the determinant factors of vaccination coverage among children aged 12 
Table 1 Socio-demographic and economic characteristics of parents and children aged 12-23 months in Ethiopia, 2016EDHS

\begin{tabular}{|c|c|c|c|}
\hline Variable & Categories & Frequency & Percentage \\
\hline \multirow[t]{3}{*}{ Highest educational level } & No education & 1170 & 60.7 \\
\hline & Primary & 508 & 26.3 \\
\hline & Secondary and above & 251 & 13.0 \\
\hline \multirow[t]{3}{*}{ Respondent's current age } & $15-24$ & 546 & 28.3 \\
\hline & $25-34$ & 978 & 50.7 \\
\hline & $35-49$ & 405 & 21.0 \\
\hline \multirow[t]{3}{*}{ Number of living children } & $1-2$ & 786 & 40.7 \\
\hline & $3-4$ & 560 & 29.0 \\
\hline & $5+$ & 583 & 30.2 \\
\hline \multirow[t]{2}{*}{ Mother occupational status } & No & 1362 & 70.6 \\
\hline & Yes & 567 & 29.4 \\
\hline \multirow[t]{2}{*}{ Place of delivery } & Home & 1101 & 57.1 \\
\hline & Health facility & 828 & 42.9 \\
\hline \multirow[t]{2}{*}{ Sex of household head } & Male & 1509 & 78.2 \\
\hline & Female & 420 & 21.8 \\
\hline \multirow[t]{3}{*}{ Wealth index combined } & poor & 979 & 50.8 \\
\hline & Middle & 279 & 14.5 \\
\hline & Rich & 671 & 34.8 \\
\hline \multirow[t]{3}{*}{ Antenatal Care visits } & No antenatal visits & 690 & 35.8 \\
\hline & $1-3$ & 541 & 28.0 \\
\hline & 4 and above & 698 & 36.2 \\
\hline \multirow[t]{3}{*}{ Husband education level } & No education & 974 & 50.5 \\
\hline & Primary & 586 & 30.4 \\
\hline & Secondary and above & 369 & 19.1 \\
\hline \multirow[t]{2}{*}{ Postnatal Care } & No & 1652 & 85.6 \\
\hline & Yes & 277 & 14.4 \\
\hline \multirow[t]{2}{*}{ Current marital status } & Not Married & 128 & 6.6 \\
\hline & Married & 1801 & 93.4 \\
\hline \multirow[t]{2}{*}{ Sex of child } & Male & 946 & 49.0 \\
\hline & Female & 983 & 51.0 \\
\hline \multirow[t]{3}{*}{ Birth order number } & First & 416 & 21.6 \\
\hline & $2-3$ & 600 & 31.1 \\
\hline & 4 abd above & 913 & 47.3 \\
\hline \multirow[t]{2}{*}{ Presence of vaccination document } & No & 1080 & 56.0 \\
\hline & Yes & 849 & 44.0 \\
\hline \multirow[t]{2}{*}{ Wanted last child } & Yes & 1546 & 80.1 \\
\hline & No & 383 & 19.9 \\
\hline \multirow[t]{3}{*}{ Relationship to household head } & Head & 319 & 16.5 \\
\hline & Wife & 1392 & 72.2 \\
\hline & Others & 218 & 11.3 \\
\hline \multirow[t]{3}{*}{ Religion } & Orthodox & 607 & 31.5 \\
\hline & Muslin & 921 & 47.7 \\
\hline & Protestant and others & 401 & 20.8 \\
\hline Size of child at birth & Small & 541 & 28.0 \\
\hline
\end{tabular}


Table 1 Socio-demographic and economic characteristics of parents and children aged 12-23 months in Ethiopia, 2016EDHS (Continued)

\begin{tabular}{|c|c|c|c|}
\hline Variable & Categories & Frequency & Percentage \\
\hline & Average & 789 & 40.9 \\
\hline & Large & 599 & 31.1 \\
\hline \multirow[t]{3}{*}{ Tetanus injections before birth } & Not received & 809 & 41.9 \\
\hline & $1-2$ & 594 & 30.8 \\
\hline & 3 and above & 526 & 27.3 \\
\hline \multirow[t]{2}{*}{ Ever had a terminated pregnancy } & No & 1770 & 91.8 \\
\hline & Yes & 159 & 8.2 \\
\hline \multirow[t]{2}{*}{ Received Vitamin A1 } & No & 929 & 48.2 \\
\hline & Yes & 1000 & 51.8 \\
\hline \multirow[t]{2}{*}{ Husband/partner's occupation } & No & 197 & 10.2 \\
\hline & Yes & 1732 & 89.8 \\
\hline \multirow[t]{2}{*}{ Type of place of residence } & Urban & 409 & 21.2 \\
\hline & Rural & 1520 & 78.8 \\
\hline \multirow[t]{11}{*}{ Region } & Tigray & 216 & 11.2 \\
\hline & Afar & 171 & 8.9 \\
\hline & Amhara & 178 & 9.2 \\
\hline & Oromia & 287 & 14.9 \\
\hline & Somali & 223 & 11.6 \\
\hline & Benishangul & 156 & 8.1 \\
\hline & SNNPR & 231 & 12.0 \\
\hline & Gambela & 138 & 7.2 \\
\hline & Harari & 117 & 6.1 \\
\hline & Addis Adaba & 102 & 5.3 \\
\hline & Dire Dawa & 110 & 5.7 \\
\hline \multirow[t]{2}{*}{ Media exposure } & No & 1265 & 65.6 \\
\hline & Yes & 664 & 34.4 \\
\hline
\end{tabular}

23 months in Ethiopia using the EDHS-2016 dataset. In Ethiopia, the prevalence of full vaccination coverage was $48.6 \%$ which indicated that childhood vaccination coverage increased in 2016 compared with 2000, 2005, and 2011 which were 14,20 , and $24 \%$ respectively. This can be attributed to the health extension program implementation that increased maternal understanding of the value of child vaccination. This vaccination coverage is lower than $79 \%$ in Kenya [31], 51\% in Malawi [32], 54\% in Uganda [33] and $86.4 \%$ in Malaysia [34]. The variations in these coverage rates may be explained by the difference in the data generation processes, the difference between these countries in the coverage of health services including the vaccination program, and the nature of the survey.

The level of parental education positively associated with child vaccination, children born from educated parents were more likely to vaccinate as compared with children born from none-educated counterparts. This supports previous findings where a higher level of maternal and father education is associated with a higher odd of child vaccination [12, 14, 15, 35-38]. The potential reason for this might be the fact that the educated parents may have knowledge of vaccination and child protection and may benefit from full vaccination for their children. The result also showed that children from Orthodox Cristiana religion were more fully immunized compared to other religious groups and this result is consistent with the literature reviewed and contribution from different studies on religion [36, 38]. The attribute of this result needs further investigation.

Children born in a health facility were more likely to vaccinate than those born at home. This is inlined with a finding from previous studies which found that institutional delivery increased the chances of children being fully vaccinated also increased [12, 14, 16, 35, 39-41]. As opposed to those who do not attend health facilities, women who visit health facilities have access to or are 
Table 2 Result of multilevel ordinal logistic regression on child vaccination in Ethiopia, EDHS 2016

\begin{tabular}{|c|c|c|c|c|}
\hline Variables & $\begin{array}{l}\text { Model I } \\
\text { AOR (95\% Cl) }\end{array}$ & $\begin{array}{l}\text { Model II } \\
\text { AOR }(95 \% \mathrm{Cl})\end{array}$ & $\begin{array}{l}\text { Model III } \\
\text { AOR }(95 \% \mathrm{Cl})\end{array}$ & $\begin{array}{l}\text { Model IV } \\
\text { AOR }(95 \% \mathrm{CI}\end{array}$ \\
\hline \multicolumn{5}{|l|}{ Place of delivery } \\
\hline Home & & 1 & & 1 \\
\hline Health facility & & $1.497(1.131,1.982)^{\mathrm{a}}$ & & $2.345(1.766,3.114)^{a}$ \\
\hline \multicolumn{5}{|l|}{ Antenatal Care visits } \\
\hline No antenatal visits & & 1 & & 1 \\
\hline $1-3$ & & $2.188(1.612,2.968)^{a}$ & & $2.069(1.523,2.810)^{\mathrm{a}}$ \\
\hline 4 and above & & $3.043(2.198,4.214)^{a}$ & & $2.657(1.906,3.704)^{\mathrm{a}}$ \\
\hline \multicolumn{5}{|c|}{ Presence of vaccination document } \\
\hline No & & 1 & & 1 \\
\hline Yes & & $5.184(4.011,6.700)^{\mathrm{a}}$ & & $4.590(3.548,5.939)^{\mathrm{a}}$ \\
\hline \multicolumn{5}{|l|}{ Wanted last child } \\
\hline No & & 1 & & 1 \\
\hline Yes & & $1.390(1.047,1.847)^{\mathrm{a}}$ & & $1.436(1.079,1.911)^{a}$ \\
\hline \multicolumn{5}{|c|}{ Tetanus injections before birth } \\
\hline Not received & & 1 & & 1 \\
\hline $1-2$ & & $1.307(0.968,1.764)$ & & $1.361(1.007,1.839)^{\mathrm{a}}$ \\
\hline 3 and above & & $1.577(1.171,2.122)^{a}$ & & $1.584(1.173,2.137)^{\mathrm{a}}$ \\
\hline \multicolumn{5}{|l|}{ Educational status } \\
\hline No education & & 1 & & 1 \\
\hline Primary & & $1.514(1.138,2.014)^{\mathrm{a}}$ & & $1.510(1.134,2.011)^{a}$ \\
\hline Secondary and above & & $2.051(1.252,3.359)^{a}$ & & $2.008(1.209,3.334)^{a}$ \\
\hline \multicolumn{5}{|l|}{ Occupational status } \\
\hline Employed & & 1 & & 1 \\
\hline Housewife & & $1.372(1.062,1.772)^{a}$ & & $1.522(1.139,2.034)^{\mathrm{a}}$ \\
\hline \multicolumn{5}{|l|}{ Wealth index } \\
\hline Poor & & 1 & & 1 \\
\hline Middle & & $1.717(1.230,2.397)^{a}$ & & $1.446(1.045,2.002)^{\mathrm{a}}$ \\
\hline Rich & & $2.085(1.476,2.944)^{\mathrm{a}}$ & & $1.679(1.233,2.287)^{a}$ \\
\hline \multicolumn{5}{|c|}{ Husband education level } \\
\hline No education & & 1 & & 1 \\
\hline Primary & & $1.369(1.046,1.790)^{a}$ & & $1.596(1.215,2.096)^{a}$ \\
\hline Secondary and above & & $2.158(1.782,2.535)^{a}$ & & $1.551(1.053,2.283)^{\mathrm{a}}$ \\
\hline \multicolumn{5}{|l|}{ Religion } \\
\hline Orthodox & & 1 & & 1 \\
\hline Muslin & & $0.549(0.396,0.761)^{a}$ & & $0.445(0.305,0.649)^{a}$ \\
\hline Protestant and others & & $0.565(0.388,0.822)^{a}$ & & $0.444(0.290,0.678)^{a}$ \\
\hline \multicolumn{5}{|l|}{ Region } \\
\hline Tigray & & & 1 & 1 \\
\hline Afar & & & $0.035(0.017,0.075)^{a}$ & $0.117(0.055,0.250)^{a}$ \\
\hline Amhara & & & $0.319(0.155,0.656)^{a}$ & $0.517(0.279,0.959)^{\mathrm{a}}$ \\
\hline Oromia & & & $0.111(0.057,0.216)^{a}$ & $0.234(0.121,0.453)^{a}$ \\
\hline Somali & & & $0.088(0.043,0.177)^{a}$ & $0.285(0.136,0.596)^{a}$ \\
\hline Benishangul & & & $0.663(0.307,1.431)$ & $1.067(0.525,2.168)$ \\
\hline
\end{tabular}


Table 2 Result of multilevel ordinal logistic regression on child vaccination in Ethiopia, EDHS 2016 (Continued)

\begin{tabular}{|c|c|c|c|c|}
\hline Variables & $\begin{array}{l}\text { Model I } \\
\text { AOR (95\% CI) }\end{array}$ & $\begin{array}{l}\text { Model II } \\
\text { AOR }(95 \% \mathrm{Cl})\end{array}$ & $\begin{array}{l}\text { Model III } \\
\text { AOR }(95 \% \mathrm{CI})\end{array}$ & $\begin{array}{l}\text { Model IV } \\
\text { AOR }(95 \% \mathrm{Cl}\end{array}$ \\
\hline SNNPR & & & $0.348(0.176,0.690)^{a}$ & $0.735(0.369,1.463)$ \\
\hline Gambela & & & $0.096(0.045,0.204)^{a}$ & $0.170(0.080,0.360)^{a}$ \\
\hline Harari & & & $0.271(0.118,0.625)^{a}$ & $0.512(0.225,1.165)$ \\
\hline Addis Adaba & & & $0.943(0.317,2.806)$ & $0.779(0.290,2.093)$ \\
\hline Dire Dawa & & & $1.111(0.437,2.826)$ & $1.020(0.414,2.512)$ \\
\hline \multicolumn{5}{|c|}{ Place of residence } \\
\hline Urban & & & 1 & 1 \\
\hline Rural & & & $0.378(0.226,0.632)^{a}$ & $0.505(0.284,0.898)^{a}$ \\
\hline \multicolumn{5}{|c|}{ Community level wealth index } \\
\hline Low & & & 1 & 1 \\
\hline High & & & $2.636(1.720,4.039)^{\mathrm{a}}$ & $2.158(1.333,3.491)^{\mathrm{a}}$ \\
\hline \multicolumn{5}{|c|}{ Community level maternal education } \\
\hline Low & & & 1 & 1 \\
\hline High & & & $1.957(1.281,2.989)^{a}$ & $1.814(1.206,2.729)^{a}$ \\
\hline \multicolumn{5}{|c|}{ Community level media exposure } \\
\hline Low & & & 1 & 1 \\
\hline High & & & $2.108(1.349,3.296)^{\mathrm{a}}$ & $1.758(1.135,2.725)^{a}$ \\
\hline
\end{tabular}

$1=$ reference category of the categorical variable

${ }^{a}$ Significant at $5 \%$ level of significance

exposed to sexual and reproductive health services [40]. Similarly, Increase the number of antenatal visits during pregnancy raises the odds of being fully immunized, a finding that is also confirmed by previous researches [12, 14, 15, 35, 39-43]. A woman provides not only professional care but also advice and education to use postnatal care and vaccination services during institutional delivery. Women who give birth at the health facility often receive details about the schedule and the significance of completing the recommended vaccination [14]. And infants born in a health facility also received the first dose of Hepatitis $\mathrm{B}$ within $12 \mathrm{~h}$ after birth, BCG, and Polio vaccine when the infant was released [13].
Mothers who received tetanus injections before birth were significantly associated with childhood vaccination. It is learned that increase in the number of received tetanus injections before birth rise the likelihood of childhood to be vaccinated, a finding that is also confirmed by previous researches $[27,43]$. This might be because mothers visiting tetanus toxoid vaccination at health facilities during pregnancy may be exposed to knowledge about the benefit of childhood vaccination.

The study also revealed that wealth index was an important variable predicts child vaccination. A higher percentage of vaccination coverage was found among children belonging to a higher wealth index as compared to their counterparts. This confirms previous findings

Table 3 Measures of variation and model fit statistics on child vaccination in Ethiopia

\begin{tabular}{|c|c|c|c|c|}
\hline Measure of variation & Model I & Model II & Model III & Model IV \\
\hline Variance (SE) & $4.167(0.531)^{*}$ & $0.979(0.200)^{*}$ & $1.641(0.258)^{*}$ & $0.428(0.173)^{*}$ \\
\hline PCV (\%) & Reference & 76.51 & 60.62 & 89.73 \\
\hline ICC (\%) & 55.88 & 22.93 & 33.28 & 11.51 \\
\hline MOR & 6.95 & 2.56 & 3.38 & 1.86 \\
\hline Score test for proportional oddsassumption & & $\begin{array}{l}X^{2}(10)=7.7 \\
P \text {-value }=0.651\end{array}$ & $\begin{array}{l}X^{2}{ }_{(12)}=21.039 \\
P \text {-value }=0.052\end{array}$ & $\begin{array}{l}X^{2}(26)=35.043 \\
P \text {-value }=0.069\end{array}$ \\
\hline \multicolumn{5}{|l|}{ Model fit statistics } \\
\hline DIC (-2log likelihood) & 3414.892 & 2891.83 & 3079.304 & 2799.66 \\
\hline AIC & 3420.892 & 2929.831 & 3115.305 & 2859.66 \\
\hline
\end{tabular}

*reference $P$-value $<0.0001$ 
where the odd of childhood vaccination increase with an increase in family income [12, 14, 15, 27, 37, 44].

This could be because children with the lowest family income status have been disadvantage and health services have been difficult to access. Poor families could spend high costs and time to preserve their daily lives. The result also showed that children born from working mothers had a lower odd of vaccination than those of non-working mothers, which confirms with findings from previous studies in Ghana [25], where the working status of the mother is negatively associated with child vaccination.

The current study showed that the presence of vaccination documents was significantly associated with childhood vaccination. Mothers who have shown vaccination documents of their children were more likely to fully vaccinate their children as compared to those who were not able to show their children's vaccination documents. This supports previous findings where the odds of full vaccination were higher in children born to mothers who had vaccination documents as compared to children born to mothers who had no vaccination documents in Ethiopia [36, 44]. This may be simple to recognize and inform mothers with a vaccination card at a house to house visiting times for health extenuation workers. Mothers with a vaccination document will easily recall the appointment of their child and thus help them complete the vaccination of their child [36]. The type of pregnancy was significantly associated with childhood vaccination. Wanted pregnancies were three times more likely to be vaccinated when compared to unwanted pregnancies. The result is in line with a previous study done in Debre Markos, Ethiopia [42].

Children living in urban areas have been reported to have better vaccination status compared with their rural areas. This finding supports studies in Ethiopia [12] and Afghanistan [11], total vaccination level in urban residence was always higher than in rural residence. This might be due to the fact that urban areas have better access to health facilities and health care practitioners than rural areas. Besides, geographical regions were statistically associated with childhood vaccination. Children living in Afar, Amhara, Oromia, Somali, Gambela were less likely to be vaccinated as compared to children living in Tigray. The result is consistent with a previous study done in Ethiopia [36]. The potential explanation for this regional variation is that there is a discrepancy between regions in the coverage of health services including the vaccination program.

Community-level maternal education, media exposures and wealth index was a strong predictor of child vaccination. Higher community-level maternal education showed a higher odd of child vaccination. Besides, increased media exposure in the community might help to increase the odds of child vaccination in that community. Furthermore, a high concentration of wealth index in a community positively influences child vaccination in that community. Children residing in communities with a high proportion of wealth index had higher odds vaccinated as compared to children residing in communities with a low proportion of wealth index. This is in line with other studies conducted in Ethiopia [36] and the Democratic Republic of Congo [14]. There are poorer health facilities in economically poorer communities; even the distance to the health facilities would be far away. Poorer areas will not invest in education for women, and empowerment for women will be lower [36].

\section{Conclusion}

In this study the coverage of child vaccination was low. Place of delivery, maternal education, number of ANC visits, presence of vaccination card, maternal occupation, mother and father education, wealth index, exposure to mass media, mothers tetanus injections received, wanted last-child, place of residence, community-level maternal education, community-level wealth index, communitylevel media exposure, and geographic region were factors significantly associated with childhood vaccination. Therefore, there is a need to increase child vaccination coverage by promoting institutional delivery and prenatal care visits, as well as maternal tetanus immunization. Besides, public initiatives needed to improve child vaccination coverage, women's and husband's education, poor women, and further advancement of health care services for poor women, housewife women, women living in remote areas should be made to maintain further improvements in child vaccination. Furthermore, policies and programs aimed at addressing cluster variations in child vaccination need to be formulated and their implementation must be strongly pursued.

\section{Abbreviations \\ AIC: Akaike's information criterion; AOR: Adjusted odds ratio; Cl: Confidence intervals; DIC: Deviance information criterion; EAs: Enumeration areas; EDHS: Ethiopian demographic and health survey; FP: Family Planning; ICC: Intra-clustercorrelation; MOR: Median odds ratio; PCV: Proportional change in variance; SNNPR: SouthernNations, Nationalities, and People Region}

\section{Acknowledgments \\ We would like to thank the Ministry of Health and Central Statistical Agency, Government of Ethiopia, for making the data freely available for research} purposes.

Authors' contributions

SM planned the study, managed and analyzed the data and manuscript writing.HM edits the manuscript. Both authors read and approved the final manuscript.

\section{Funding}

None. 


\section{Availability of data and materials}

The survey datasets used in this study was based on a publicly availabledataset that is freely available online with no participant's identity fromhttp://www. dhsprogram.com/data/available-datasets.cfm.Approval was sought from MEASURE DHS/ICF International and permissionwas granted for this use.

\section{Declarations}

\section{Ethics approval and consent to participate}

This study is a secondary data analysis of the EDHS, which is publicly available, approval was sought from MEASURE DHS/ICF International and permission was granted for this use. The original DHS data were collected in conformity with international and national ethical guidelines. Ethical clearance was provided by the Ethiopian Public Health Institute (EPHI) (formerly the Ethiopian Health and Nutrition Research Institute (EHNRI) Review Board, the National Research Ethics Review Committee (NRERC) at the Ministry of Science and Technology, the Institutional Review Board of ICF International, and the United States Centers for Disease Control and Prevention (CDC). Written consent was obtained from mothers/caregivers and data were recorded anonymously at the time of data collection during the EDHS 2016.

\section{Consent for publication}

Not applicable.

\section{Competing interests}

The authors declare that no competing interests exist.

\section{Author details}

'Department of Statistics, Faculty of Natural and Computational Sciences, Debre Tabor University, Debre Tabor, Ethiopia. ${ }^{2}$ Department of Statistics, College of Science, Bahir Dar University, Bahir Dar, Ethiopia.

Received: 11 December 2020 Accepted: 13 April 2021

Published online: 20 April 2021

\section{References}

1. Khazaei Z, et al. Global cancer statistics 2018: Globocan estimates of incidence and mortality worldwide prostate cancers and their relationship with the human development index. Adv Hum Biol. 2019;9(3):245.

2. Yaya S, Uthman OA, Okonofua F, Bishwajit G. Decomposing the rural-urban gap in the factors of under-five mortality in sub-Saharan Africa? Evidence from 35 countries. BMC Public Health. 2019;19(1):616. https://doi.org/10.11 86/s12889-019-6940-9.

3. Ezbakhe F, Pérez-Foguet A. Child mortality levels and trends. Demogr Res. 2020:43:1263-96. https://doi.org/10.4054/DemRes.2020.43.43.

4. Nour TY, et al. Predictors of immunization coverage among 12-23 month old children in Ethiopia: systematic review and meta-analysis. BMC Public Health. 2020;20(1):1-19.

5. Mekonnen ZA, et al. Timely completion of vaccination and its determinants among children in northwest, Ethiopia: a multilevel analysis. BMC Public Health. 2020;20(1):1-13.

6. Shen AK, Fields R, McQuestion M. The future of routine immunization in the developing world: challenges and opportunities. Glob Health Sci Pract. 2014:2(4):381-94.

7. Lim SS, Stein DB, Charrow A, Murray CJL. Tracking progress towards universal childhood immunisation and the impact of global initiatives: a systematic analysis of three-dose diphtheria, tetanus, and pertussis immunisation coverage. Lancet. 2008;372(9655):2031-46. https://doi.org/10.1 016/S0140-6736(08)61869-3.

8. Li X, Mukandavire C, Cucunubá ZM, Echeverria Londono S, Abbas K, Clapham $\mathrm{HE}$, et al. Estimating the health impact of vaccination against ten pathogens in 98 low-income and middle-income countries from 2000 to 2030: a modelling study. Lancet. 2021;397(10272):398-408. https://doi.org/1 0.1016/S0140-6736(20)32657-X

9. Ararat M. The Global Context: Sustainable Development Goals and Gender Equality, in Business Against Intimate Partner Violence: Springer; 2020. p. 5-17.

10. Wondimu A, Cao Q, Asuman D, Almansa J, Postma MJ, van Hulst M. Understanding the improvement in full childhood vaccination coverage in Ethiopia using Oaxaca-blinder decomposition analysis. Vaccines. 2020;8(3): 505. https://doi.org/10.3390/vaccines8030505.
11. Aalemi AK, Shahpar K, Mubarak MY. Factors influencing vaccination coverage among children age 12-23 months in Afghanistan: analysis of the 2015 demographic and health survey. PLoS One. 2020;15(8):e0236955. https://doi.org/10.1371/journal.pone.0236955.

12. Debie A, Lakew AM. Factors associated with the access and continuum of vaccination services among children aged 12-23 months in the emerging regions of Ethiopia: evidence from the 2016 Ethiopian demography and health survey. Ital J Pediatr. 2020;46(1):1-11.

13. Efendi F, Pradiptasiwi DR, Krisnana I, Kusumaningrum T, Kurniati A, Sampurna MTA, et al. Factors associated with complete immunizations coverage among Indonesian children aged 12-23 months. Child Youth Serv Rev. 2020;108:104651. https://doi.org/10.1016/j.childyouth.2 019.104651.

14. Acharya P, Kismul H, Mapatano MA, Hatløy A. Individual-and communitylevel determinants of child immunization in the Democratic Republic of Congo: a multilevel analysis. PLoS One. 2018;13(8):e0202742. https://doi. org/10.1371/journal.pone.0202742.

15. Desalegn $T$, et al. Vaccination coverage and associated factors among children in Debre Berhan town, Ethiopia. Recent Adv Biol Med. 2019;5(2019): 11536.

16. Noh J-W, Kim YM, Akram N, Yoo KB, Cheon J, Lee LJ, et al. Determinants of timeliness in early childhood vaccination among mothers with vaccination cards in Sindh province, Pakistan: a secondary analysis of cross-sectional survey data. BMJ Open. 2019;9(9):e028922. https://doi.org/10.1136/ bmjopen-2019-028922.

17. Nozaki I, Hachiya M, Kitamura T. Factors influencing basic vaccination coverage in Myanmar: secondary analysis of 2015 Myanmar demographic and health survey data. BMC Public Health. 2019;19(1):1-8.

18. Fenta SM, Fenta HM. Risk factors of child mortality in Ethiopia: application of multilevel two-part model. PLoS One. 2020;15(8):e0237640. https://doi.org/1 0.1371/journal.pone.0237640.

19. Fenta SM, Biresaw HB, Fentaw KD. Risk factor of neonatal mortality in Ethiopia: multilevel analysis of 2016 demographic and health survey. Trop Med Health. 2021:49(1):1-11.

20. Adedokun ST, et al. Incomplete childhood immunization in Nigeria: a multilevel analysis of individual and contextual factors. BMC Public Health. 2017;17(1):1-10.

21. Restrepo-Méndez MC, Barros AJD, Wong KLM, Johnson HL, Pariyo G, Wehrmeister FC, et al. Missed opportunities in full immunization coverage: findings from low-and lower-middle-income countries. Glob Health Action. 2016;9(1):30963. https://doi.org/10.3402/gha.v9.30963.

22. Tamirat KS, Sisay MM. Full immunization coverage and its associated factors among children aged 12-23 months in Ethiopia: further analysis from the 2016 Ethiopia demographic and health survey. BMC Public Health. 2019; 19(1):1-7.

23. Atnafu A, Andargie G, Yitayal M, Ayele TA, Alemu K, Demissie GD, et al. Prevalence and determinants of incomplete or not at all vaccination among children aged 12-36 months in Dabat and Gondar districts, northwest of Ethiopia: findings from the primary health care project. BMJ Open. 2020; 10(12):e041163. https://doi.org/10.1136/bmjopen-2020-041163.

24. Gilbert NL, Gilmour H, Wilson SE, Cantin L. Determinants of non-vaccination and incomplete vaccination in Canadian toddlers. Hum Vaccines Immunotherapeutics. 2017;13(6):1447-53. https://doi.org/10.1080/2164551 5.2016.1277847

25. Anokye R, Acheampong E, Budu-Ainooson A, Edusei AK, Okyere P, Dogbe J, et al. Socio-demographic determinants of childhood immunization incompletion in Koforidua, Ghana. BMC Res Notes. 2018;11(1):656. https:// doi.org/10.1186/s13104-018-3767-x

26. Eshete A, Shewasinad S, Hailemeskel S. Immunization coverage and its determinant factors among children aged 12-23 months in Ethiopia: a systematic review, and meta-analysis of cross-sectional studies. BMC Pediatr. 2020;20(1):1-13.

27. Nozaki I, Hachiya M, Kitamura T. Factors influencing basic vaccination coverage in Myanmar: secondary analysis of 2015 Myanmar demographic and health survey data. BMC Public Health. 2019;19(1):242. https://doi.org/1 0.1186/s12889-019-6548-0.

28. Mekonnen AG, Bayleyegn AD, Ayele ET. Immunization coverage of 12-23 months old children and its associated factors in Minjar-Shenkora district, Ethiopia: a community-based study. BMC Pediatr. 2019;19(1):1-8.

29. Dessie ZG, et al. Multilevel ordinal model for CD4 count trends in seroconversion among South Africa women. BMC Infect Dis. 2020;20(1):1-12. 
30. Tirore LL, Mulugeta A, Belachew AB, Gebrehaweria M, Sahilemichael A, Erkalo D, et al. Factors associated with anaemia among women of reproductive age in Ethiopia: multilevel ordinal logistic regression analysis. Matern Child Nutr. 2021:17(1):e13063. https://doi.org/10.1111/mcn.13063.

31. Ochako R, Fotso JC, Ikamari L, Khasakhala A. Utilization of maternal health services among young women in Kenya: insights from the Kenya demographic and health survey, 2003. BMC Pregnancy Childbirth. 2011; 11(1):1. https://doi.org/10.1186/1471-2393-11-1.

32. Munthali AC. Determinants of vaccination coverage in Malawi: evidence from the demographic and health surveys. Malawi Med J. 2007;19(2):79-82. https://doi.org/10.4314/mmj.v19i2.10934.

33. Bbaale E. Factors influencing childhood immunization in Uganda. J Health Popul Nutr. 2013;31(1):118.

34. Lim K, et al. Complete immunization coverage and its determinants among children in Malaysia: findings from the National Health and morbidity survey (NHMS) 2016. Public Health. 2017;153:52-7. https://doi.org/10.1016/j.puhe.2 017.08.001.

35. Meleko A, Geremew M, Birhanu F. Assessment of child immunization coverage and associated factors with full vaccination among children aged 12-23 months at Mizan Aman town, bench Maji zone, Southwest Ethiopia. Int J Pediatr. 2017;2017:1-11. https://doi.org/10.1155/2017/7976587.

36. Kinfe $Y$, Gebre $H$, Bekele A. Factors associated with full immunization of children 12-23 months of age in Ethiopia: a multilevel analysis using 2016 Ethiopia demographic and health survey. PLoS One. 2019;14(11):e0225639. https://doi.org/10.1371/journal.pone.0225639.

37. Herliana P, Douiri A. Determinants of immunisation coverage of children aged 12-59 months in Indonesia: a cross-sectional study. BMJ Open. 2017; $7(12)$.

38. Mik S, Mf S, Kurlikar PR. Status and determinants of child immunisation coverage in three south Asian countries, India, Bangladesh and Nepal: evidence from the demographic and health survey. Sri Lanka J Child Heal. 2018;47:56-63.

39. Etana B, Deressa W. Factors associated with complete immunization coverage in children aged 12-23 months in ambo Woreda, Central Ethiopia. BMC Public Health. 2012;12(1):566. https://doi.org/10.1186/1471-2458-12-566.

40. Tesfaye TD, Temesgen WA, Kasa AS. Vaccination coverage and associated factors among children aged 12-23 months in Northwest Ethiopia. Hum Vaccines Immunotherapeutics. 2018;14(10):2348-54. https://doi.org/10.1 080/21645515.2018.1502528.

41. Sarker AR, Akram R, Ali N, Chowdhury ZI, Sultana M. Coverage and determinants of full immunization: vaccination coverage among Senegalese children. Medicina. 2019;55(8):480. https://doi.org/10.3390/medicina55080480.

42. Gualu T, Dilie A. Vaccination coverage and associated factors among children aged 12-23 months in debre markos town, Amhara regional state, Ethiopia. Adv Public Health. 2017;2017.

43. Hailu S, Astatkie A, Johansson KA, Lindtjørn B. Low immunization coverage in Wonago district, southern Ethiopia: a community-based cross-sectional study. PLoS One. 2019;14(7):e0220144. https://doi.org/10.1371/journal.pone. 0220144.

44. Lakew Y, Bekele A, Biadgilign S. Factors influencing full immunization coverage among 12-23 months of age children in Ethiopia: evidence from the national demographic and health survey in 2011. BMC Public Health. 2015;15(1):728. https://doi.org/10.1186/s12889-015-2078-6.

\section{Publisher's Note}

Springer Nature remains neutral with regard to jurisdictional claims in published maps and institutional affiliations.

\section{Ready to submit your research? Choose BMC and benefit from}

- fast, convenient online submission

- thorough peer review by experienced researchers in your field

- rapid publication on acceptance

- support for research data, including large and complex data types

- gold Open Access which fosters wider collaboration and increased citations

- maximum visibility for your research: over $100 \mathrm{M}$ website views per year

At BMC, research is always in progress.

Learn more biomedcentral.com/submissions 